\title{
Maternal serum progesterone, estradiol and estriol levels in successful dinoprostone-induced labor
}

\author{
C.K. Konopka ${ }^{1,2}$, E.N. Morais ${ }^{1}$, D. Naidon ${ }^{1}$, A.M. Pereira ${ }^{3}$, M.A. Rubin ${ }^{2,4}$ \\ J.F. Oliveira ${ }^{2,3}$ and C.F. Mello ${ }^{2,5}$ \\ ${ }^{1}$ Departamento de Ginecologia e Obstetrícia, Centro de Ciências da Saúde, Universidade Federal de Santa Maria, \\ Santa Maria, RS, Brasil \\ ${ }^{2}$ Programa de Pós-Graduação em Farmacologia, Centro de Ciências da Saúde, Universidade Federal de Santa Maria, \\ Santa Maria, RS, Brasil \\ ${ }^{3}$ Laboratório de Biotecnologia e Reprodução Animal, Departamento de Clínica de Grandes Animais, \\ Centro de Ciências Rurais, Universidade Federal de Santa Maria, Santa Maria, RS, Brasil \\ ${ }^{4}$ Departamento de Química, Centro de Ciências Exatas e Naturais, Universidade Federal de Santa Maria, \\ Santa Maria, RS, Brasil \\ ${ }^{5}$ Departamento de Fisiologia e Farmacologia, Centro de Ciências da Saúde, Universidade Federal de Santa Maria, \\ Santa Maria, RS, Brasil
}

\begin{abstract}
Hormone-mediated quiescence involves the maintenance of a decreased inflammatory responsiveness. However, no study has investigated whether labor induction with prostanoids is associated with changes in the levels of maternal serum hormones. The objective of this study was to determine whether labor induction with dinoprostone is associated with changes in maternal serum progesterone, estradiol, and estriol levels. Blood samples were obtained from 81 pregnant women at term. Sixteen patients had vaginal birth after spontaneous labor, 12 required cesarean section after spontaneous labor and 16 underwent elective cesarean. Thirty-seven patients had labor induction with dinoprostone. Eligible patients received a vaginal insert of dinoprostone $(10 \mathrm{mg})$ and were followed until delivery. Serum progesterone (P4), estradiol (E2) and estriol (E3) levels and changes in P4/E2, P4/E3 and E3/E2 ratios were monitored from admission to immediately before birth, and the association of these measures with the resulting clinical classification outcome (route of delivery and induction responsiveness) was assessed. Progesterone levels decreased from admission to birth in patients who underwent successful labor induction with dinoprostone [vaginal and cesarean birth after induced labor: $23 \%(P<0.001)$ and $18 \%(P<0.025)$ decrease, respectively], but not in those whose induction failed (6.4\% decrease, $P>0.05)$. Estriol and estradiol levels, P4/E2, P4/E3 and E3/E2 ratios did not differ between groups. Successful dinoprostone-induced labor was associated with reduced maternal progesterone levels from induction to birth. While a causal relationship between progesterone decrease and effective dinoprostone-induced labor cannot be established, it is tempting to propose that dinoprostone may contribute to progesterone withdrawal and favor labor induction in humans.
\end{abstract}

Key words: Labor induction; Dinoprostone, $\mathrm{PGE}_{2}$; Progesterone; Estriol; Estradiol

\section{Introduction}

Prostaglandins, particularly $\mathrm{PGF}_{2}$ and $\mathrm{PGE}_{2}$, play an essential role in the process of human parturition by stimulating myometrial contractions (1) and cervical effacement (2). Due to these properties, dinoprostone, a $\mathrm{PGE}_{2}$ analog, has become the gold standard for the induction of labor in patients with high risk pregnancies (3).
For unknown reasons, up to $33 \%$ of the patients who do not reach labor spontaneously do not respond to induction with prostaglandins and/or oxytocin (4). Although progesterone-mediated quiescence seems to involve the maintenance of a decreased inflammatory responsiveness, no study has addressed whether inflammatory mediators can alter progesterone, estradiol and

Correspondence: C.K. Konopka, Departamento de Ginecologia e Obstetrícia, Centro de Ciências da Saúde, UFSM, 97105-900 Santa Maria, RS, Brasil. Fax: +55-55-3221-5084. E-mail: cristine.ufsm@gmail.com 
estriol levels, and by this means also facilitate labor induction.

Human parturition at term requires an orchestrated set of hormonal and morphological changes that occur gradually within uterine tissues (5). These changes include increased myometrial gap junction formation (5), up-regulation of myometrial progesterone A (6), estrogen $\alpha(7)$, prostaglandin $(5,8)$, and oxytocin receptors (5). A decreased progesterone/estradiol ratio (9) and increased maternal plasma estriol (10) levels have been associated with successful labor, but there are also reports that plasma progesterone levels do not significantly decrease immediately before labor (11-13). The myometrial receptor and hormonal changes shift the uterus from a quiescent to an active rhythmically contractile state. Concomitant with these changes, inflammatory events occur in the cervix, such as increased production of proinflammatory cytokines such as interleukin-1 $\beta$ (IL-1 $\beta$ ), IL6, IL-8 (14-16), and $\mathrm{PGE}_{2}$ (15), which trigger cervical ripening.

In humans, according to some investigators, concentrations of progesterone and estrogens remain elevated in maternal plasma throughout pregnancy until delivery of the placenta $(7,17)$. Studies comparing progesterone levels during labor at term to those in the absence of labor failed to demonstrate an unequivocal variation in serum progesterone levels related to labor $(12,13)$. On the other hand, high progesterone levels at term have been associated with effective labor (11) and it has been recently observed that placentas obtained from patients who underwent vaginal delivery produce more progesterone and store larger amounts of progesterone than those from patients after cesarean delivery (18).

The apparent lack of serum progesterone withdrawal in parturient women has led to the introduction of the concept of "functional" progesterone withdrawal due to an increase in the expression of the inactive progesterone receptor PR-A $(17,19,20)$. PR-B, with predominant levels during pregnancy, is an activator of progesterone-responsive genes, while PR-A acts as a modulator or repressor of PR-B function $(6,19)$.

As we can see, the role of prostaglandins in the onset of labor is still under investigation and much more may be developed in this field of interest. One of the most important issues from this point of view is if the mode of delivery after labor induction with prostanoids could be a factor influencing hormone levels during labor. Therefore, in this study we investigated whether labor induction with dinoprostone is associated with changes in maternal serum levels of progesterone (P4), estradiol (E2), and estriol (E3) in responsive and non-responsive patients.

\section{Patients and Methods}

\section{Patients}

From January 2009 to May 2011 we enrolled 81 non- smoking pregnant women at term, with live fetuses, who gave birth at the Hospital Universitário de Santa Maria, Rio Grande do Sul State, Brazil. Some patients entered the study with spontaneous labor and others required pregnancy interruption, either by labor induction or elective cesarean section. Data for patients who required medications other than paracetamol or iron sulfate the week before the birth were not included in data analysis. Gestational age was estimated by ultrasound examination before 20 weeks of gestation. Term pregnancy was considered to be a gestational age between 37 weeks and 41 weeks and 6 days, spontaneous labor to be natural labor initiation and elective cesarean to be childbirth in the absence of labor. The Bishop score (21) was recorded at admission and at several times during labor.

Maternal P4, E2 and E3 levels were assessed at admission and immediately before birth in patients as follows: group 1 = vaginal birth after spontaneous labor; group 2 = cesarean section after spontaneous labor (due to dystocia or fetal distress); group 3 = elective cesarean; group 4 = vaginal birth after dinoprostone-induced labor; group $5=$ cesarean section after dinoprostone-induced labor (due to dystocia, fetal distress or hypertonia); group $6=$ cesarean section after dinoprostone-induction failure.

\section{Labor induction}

Patients with an indication for labor induction were assigned to receive vaginally administered dinoprostone (10 mg Propess ${ }^{\circledR}$, Ferring Pharmaceuticals, Brazil). The inclusion criteria for labor induction were: singleton gestation, cephalic presentation, estimated fetal weight $<4000 \mathrm{~g}$, intact membranes, reactive fetal heart rate pattern, and an unripe cervix, defined as a Bishop score $\leq 5$ points (21).

The vaginal insert was placed in the posterior vaginal fornix, as described before (22), and was removed when patients presented at least 3 uterine contractions within $10 \mathrm{~min}$ and adequate cervical ripening (Bishop score $\geqslant 8$ or cervical dilatation $\geqslant 3 \mathrm{~cm}$ ), or signs of fetal distress. During the second stage of labor, oxytocin was administered when necessary, in spontaneous or induced labors, regardless of the study group. The maximum time allowed for cervical ripening was $24 \mathrm{~h}$ (23) and failed labor induction was considered inadequate cervical ripening and inadequate uterine contractions during $24 \mathrm{~h}$ (nonresponders).

\section{Blood sampling}

Blood (4 mL) samples were collected by venipuncture of the median cubital vein at two distinct times: 1) at admission, from patients in spontaneous labor and who would undergo elective cesarean delivery, or before administering dinoprostone, and 2) immediately before birth in all cases. Blood samples were centrifuged at $2000 \mathrm{~g}$ at $4^{\circ} \mathrm{C}$ for $15 \mathrm{~min}$, and the serum was separated 
and maintained at $-80^{\circ} \mathrm{C}$ until assay.

\section{Assay methods}

Progesterone and estradiol were measured using the Bayer ADVIA Centaur assay (Bayer Corp., USA), a competitive immunoassay using direct chemiluminescent technology. Total estriol was measured using fluorescence polarization immunoassay technology and the Abbott TDxFLx analyzer (Abbott Laboratories, USA). Sensitivity and inter-assay coefficient of variation for progesterone, estradiol and estriol assays were 0.67 , 25.7 and $22.9 \mathrm{nM}$ and 5.3, 8.4 and $2.3 \%$, respectively.

\section{Ethics statement}

Research was approved by the Ethics Committee from Universidade Federal de Santa Maria (CAAE 0268. 0.243.000-08), and written informed consent was obtained from all participants before enrollment. Dinoprostone was acquired with funds from CNPq (Conselho Nacional de Pesquisa). The authors have no conflict of interest with the laboratory that manufactures dinoprostone

\section{Statistical analysis}

Quantitative parametric data are reported as means \pm SE. Data were analyzed by two-way analysis of variance (ANOVA), with the "measures" factor treated as within-subject factor. Data were subjected to logarithmic transformation in order to meet ANOVA assumptions. Post hoc analyses of within-subject effects were carried out by the F-test for simple effect. Nonparametric data were analyzed by the Kruskal-Wallis test followed by the Dunn nonparametric multiple comparison test. The level of significance was set as $P<0.05$, and $F$ and $\mathrm{H}$ values are shown only if statistical significance was achieved.

\section{Results}

A total of 81 pregnant women were recruited. Sixteen patients had vaginal birth after spontaneous labor, 12 required cesarean section after spontaneous labor and 16 underwent elective cesarean, for a total of 44 patients who did not require labor induction. Thirty-seven patients were selected for labor induction with dinoprostone according to the eligibility criteria and protocol described above. Fifteen patients progressed to vaginal birth, 12 required cesarean section after successful labor induction and 10 had failure of labor induction and therefore underwent cesarean section (Table 1).

Mean maternal age and gestational age at delivery were similar among groups (Table 1). Statistical analysis revealed that time between blood sampling for dinoprostone-induced labors was longer than for spontaneous labors $(P<0.001)$, regardless of route of delivery (Table 1). Parity also differed between groups that received dinoprostone or not. Sample analysis revealed that patients subjected to labor induction with dinoprostone were all nulliparous, while most of the patients who did not receive dinoprostone were multiparous $(P<0.001)$. Oxytocin administration showed no differences between labor groups regarding parity, gestational age at delivery or time between samples (data not shown). The observation of significant differences between groups such as parity, interval between blood samples and Bishop scores is inherent to the clinical characteristics of each group.

Statistical analysis of Bishop scores along time showed a significant difference between groups by time interaction $[\mathrm{F}(1,75)=40.9 ; \mathrm{P}<0.001)]$. Post hoc analysis (F-test for simple effect) revealed that all patients, except those who underwent elective cesarean, had an increased Bishop score along time (Table 2). Interestingly, although patients who were considered non-

Table 1. Maternal age, gestational age, time between samplings, and parity of patients with and without dinoprostone treatment.

\begin{tabular}{|c|c|c|c|c|c|c|c|}
\hline \multirow[t]{3}{*}{ Variable } & \multicolumn{3}{|c|}{ No dinoprostone } & \multicolumn{3}{|c|}{ Dinoprostone } & \multirow[t]{3}{*}{$P$} \\
\hline & \multicolumn{2}{|c|}{ After spontaneous labor } & \multirow{2}{*}{$\begin{array}{c}\text { No spontaneous labor } \\
\text { Cesarean } \\
(\mathrm{n}=16)\end{array}$} & \multicolumn{2}{|c|}{ After induced labor } & \multirow{2}{*}{$\begin{array}{c}\text { After induction failure } \\
\begin{array}{c}\text { Cesarean } \\
(\mathrm{n}=10)\end{array}\end{array}$} & \\
\hline & $\begin{array}{l}\text { Vaginal birth } \\
\quad(\mathrm{n}=16)\end{array}$ & $\begin{array}{l}\text { Cesarean } \\
(\mathrm{n}=12)\end{array}$ & & $\begin{array}{l}\text { Vaginal birth } \\
(\mathrm{n}=15)\end{array}$ & $\begin{array}{l}\text { Cesarean } \\
(n=12)\end{array}$ & & \\
\hline $\begin{array}{l}\text { Maternal age } \\
\text { (years) }\end{array}$ & $24.5 \pm 6.7$ & $23.7 \pm 4.9$ & $27.6 \pm 6.7$ & $22.7 \pm 5.4$ & $23.5 \pm 4.8$ & $24.8 \pm 5.2$ & \\
\hline $\begin{array}{l}\text { Gestational } \\
\text { age (weeks) }\end{array}$ & $39.5 \pm 1.4$ & $39.8 \pm 1.3$ & $39.9 \pm 1.3$ & $39.9 \pm 1.3$ & $39.5 \pm 1.5$ & $39.8 \pm 1.3$ & \\
\hline $\begin{array}{l}\text { Time between } \\
\text { samplings }(\mathrm{h})\end{array}$ & $5(3-8.7)^{\mathrm{b}}$ & $5.5(3.2-7)^{a . b}$ & $3(1-6.7)^{\mathrm{a}}$ & $16(12-20)^{\mathrm{C}}$ & $19.5(12.5-23)^{\mathrm{c}}$ & $24(21.5-26)^{\mathrm{C}}$ & $<0.01^{*}$ \\
\hline Parity & $1(0-1)^{b}$ & $1(0-1)^{b}$ & $1(0-2)^{b}$ & $0(0-0)^{a}$ & $0(0-0)^{a}$ & $0(0-0)^{a}$ & $<0.01^{*}$ \\
\hline
\end{tabular}

Data are reported as means \pm SE or as median (interquatile range). There were no significant differences among groups for maternal age or gestational age (one-way ANOVA). ${ }^{*}$ Time between blood samplings and parity were analyzed by the Kruskal-Wallis test. Different superscript letters indicate significant differences by the Dunn nonparametric multiple comparison test $(P<0.05)$. 
Table 2. Bishop scores at admission and immediately before birth of patients with and without dinoprostone treatment.

\begin{tabular}{lcrr}
\hline Groups & Admission & Birth & $P$ \\
\hline Vaginal birth after spontaneous labor & $6.88 \pm 1.36$ & $10.7 \pm 0.59$ & $<0.001$ \\
Cesarean after spontaneous labor & $5.83 \pm 2.17$ & $7.42 \pm 2.71$ & $<0.001$ \\
Elective cesarean & $2.44 \pm 1.03$ & $2.44 \pm 1.03$ & 1.000 \\
Vaginal birth after dinoprostone induction & $3.47 \pm 0.92$ & $10.7 \pm 0.46$ & $<0.001$ \\
Cesarean after dinoprostone induction & $3.00 \pm 1.08$ & $7.38 \pm 2.81$ & $<0.001$ \\
Cesarean after induction failure & $2.40 \pm 0.52$ & $3.90 \pm 1.37$ & $<0.005$ \\
\hline
\end{tabular}

Data are reported as means \pm SE and analyzed by the $t$-test for paired samples.

responders to dinoprostone induction had a significant increase in Bishop scores along time $[F(1,75)=9.22, P$ $<0.005]$, their final Bishop score still represented immature cervices (Bishop $\leq 5)$.

\section{Maternal serum levels of progesterone, estradiol and estriol}

Statistical analysis (two-way ANOVA, with the "measures" factor treated as within-subject factor) of maternal serum progesterone levels at admission and during labor (immediately before birth) revealed a significant effect of measures $[F(1,75)=18.49, P<0.001]$, indicating that progesterone levels varied from admission to delivery in at least one group. Post hoc analysis (F-test for simple effect) revealed that only parturients who responded to labor induction with dinoprostone presented a significant reduction in serum progesterone [dinoprostone and vaginal labor: $\mathrm{F}(1,75)=9.13, \mathrm{P}<0.005$; dinoprostone and cesarean: $F(1,75)=6.65, P<0.025$; Figure 1].

Statistical analysis (two-way ANOVA, with the "measures" factor treated as within-subject factor) of maternal serum estradiol levels at admission and immediately before birth revealed a significant effect of measures $[F(1,75)=17.11, P<0.01]$. However, post hoc analysis failed to show differences within groups, revealing that the

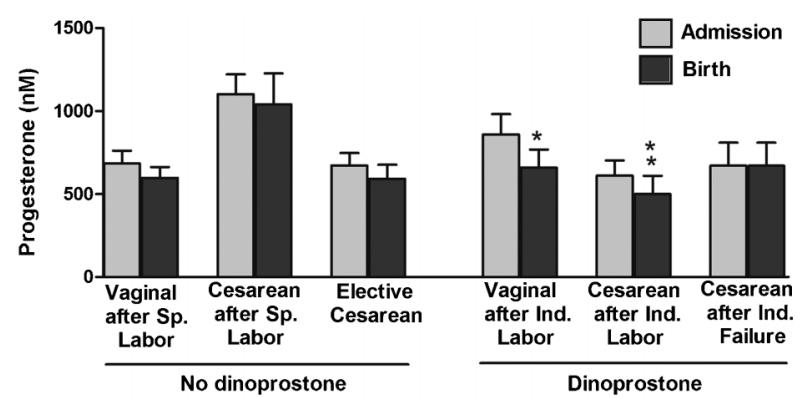

Figure 1. Maternal serum levels of progesterone at admission and immediately before birth in patients with and without dinoprostone treatment. Sp. = spontaneous; Ind. = induced or induction. ${ }^{*} P<0.005$ and ${ }^{* *} P<0.025$ compared to the respective admission mean for patients with and without dinoprostone treatment (two-way ANOVA followed by the F-test for simple effect). main effect observed was a general trend along time, irrespective of classification outcome.

Maternal levels of estriol and P4/E2, P4/E3 and E3/E2 ratios immediately before birth did not differ from admission. The use of oxytocin had no influence on hormonal levels (data not shown).

\section{Discussion}

Divergent results concerning the variation of maternal steroids and their role in human parturition have been reported. Serum estrogen levels have been reported to remain stable between the last weeks of gestation and labor $(10,13)$. Although a general trend towards a decrease in estrogen levels from admission to labor was found in the current study irrespective of outcome classification, no differences between groups were found in the post hoc analysis, confirming similar literature findings showing that estrogen levels do not change between the last weeks of gestation and labor (10) or preceding labor when compared to immediately before birth (13).

Some studies have found no differences in maternal progesterone levels during spontaneous labor $(12,13)$. In this regard, our results are in agreement with the literature, since patients who underwent spontaneous labor did not show significant alterations in the serum levels of progesterone from admission to birth.

In the present study, gestational age was estimated by early ultrasound examination ( $<20$ weeks), since last menstrual period-based (LMP-based) gestational age involves high rates of gestational age misclassification (24). Literature data show that inaccuracy of LMP-based gestational age can be caused by biologically associated errors in menstrual cycles and by human error in recall or data entry (25). Recent studies have found that early ultrasound-based gestational age formulas are fairly accurate, with random errors of \pm 10 days (95\% confidence interval) (26). Thus, while an early ultrasound may underestimate or overestimate gestational age by 10 days on average, this bias is relatively small compared to the large magnitude of error indicated by inaccurate LMP data.

As expected, the time between blood samples was 
longer in dinoprostone-induction patients than in those with spontaneous labor initiation or elective cesarean. These patients, who required labor induction, had immature cervices, requiring a longer time to prepare their cervices for vaginal labor. It is important to note that nulliparous pregnant women had more frequently immature cervices when compared to multiparous pregnant women, requiring induction with dinoprostone. This explains why our induction groups are composed of nulliparous women. In a recent study, regarding successful labor induction, most women were nulliparous and parity was noted to be the single best predictor of subsequent vaginal delivery (27).

Progesterone withdrawal has been considered a major determinant of labor initiation, since it relaxes the myometrium by repressing the expression of genes that encode factors collectively called contraction-associated proteins, which include connexin43 (28), cyclooxygenase2 (29) and oxytocin receptor (28). Moreover, increased progesterone activity is associated with increased 15hydroxyprostaglandin dehydrogenase expression, which catalyzes the conversion of $\mathrm{PGE}_{2}$ and $\mathrm{PGF}_{2} \alpha$ to their biologically inactive 15-keto derivatives in term trophoblasts (30). During spontaneous labor, although no reduction in serum progesterone levels has been observed, a parturition cascade exists, that removes the mechanisms responsible for uterine quiescence and recruits factors that initiate uterine activity, promoting the process of labor (5).

Some questions about parturition activation have been partially answered after the introduction of the "functional" progesterone withdrawal concept (31-33), that consists of myometrial sensitivity loss to progesterone due to the increased expression of the nonfunctional progesterone receptor PR-A and which results in an increased PR-A to PR-B ratio (20). This concept explains why, despite high progesterone levels, the myometrium at term loses its refractoriness in humans. The currently reported observation that dinoprostone-induced successful labor is associated with a decrease in serum maternal progesterone levels suggests that a decrease in progesterone levels may synergically facilitate "functional" progesterone withdrawal and myometrial quiescence disruption.

One possible mechanism of progesterone-mediated quiescence during pregnancy is the constitutive inhibition of the transcription nuclear factor- $\kappa \mathrm{B}(\mathrm{NF}-\kappa \mathrm{B})$ by progesterone (30). Suppression of NF- $\kappa B$ decreases cyclooxygenase-2 (COX-2) expression and, by this means, decreases prostaglandin synthesis. In amnion cells obtained before labor, in which NF-KB activity is low, increasing the expression of functional PR represses NF$\kappa \mathrm{B}$-dependent transcription, while stimulation with IL-1 $\beta$ both increases $N F-\kappa B$ activity and represses functional PR activity (34). NF- $\kappa B$ activity is observed during human labor. This mediates COX-2 expression and is involved in

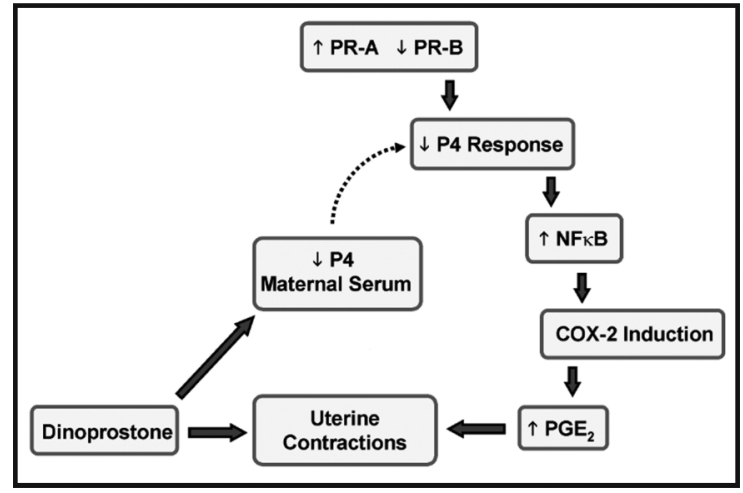

Figure 2. Possible mechanism by which dinoprostone contributes to progesterone withdrawal. An increased PR-A/PR-B ratio decreased progesterone (P4) activity by unsuppressing NF-kBmediated responses, including $\mathrm{COX}-2$ induction and increased prostanoid $\left(\mathrm{PGE}_{2}\right.$ and $\left.\mathrm{PGF}_{2}\right)$ synthesis, which cause uterine contraction. Dinoprostone, a $\mathrm{PGE}_{2}$ analogue, decreases $\mathrm{P} 4$ levels by still unknown mechanisms, which may include decreased placenta $\mathrm{P} 4$ production/secretion contributing to P4 withdrawal. $\mathrm{PR}=$ progesterone receptor; NF-kB $=$ transcription nuclear factor- $\mathrm{\kappa B}$; COX-2 = cyclooxygenase-2.

the "functional" progesterone withdrawal (35).

The exact mechanisms by which serum progesterone levels decreased in dinoprostone-responders are unknown. To our knowledge, no study has addressed whether prostanoids alter progesterone release in human trophoblast. Therefore, one might speculate that pharmacological manipulation with dinoprostone may alter progesterone production/release in human placenta.

While a causal relationship between the currently reported progesterone decrease and effective dinoprostone-induced labor cannot be established, it is tempting to propose that the dinoprostone-associated progesterone decrease may synergically contribute to "functional" progesterone withdrawal and favor labor induction in humans (Figure 2).

Actually, the lack of knowledge about this complex issue indicates that more studies should be performed to elucidate some of many unanswered questions raised by investigators around the world. Thus, it is important to consider that these questions are far from being answered.

\section{Acknowledgments}

Research supported by CNPq, PRONEX/CNPq/ FAPERGS, PROAP/CAPES, and PRPGP/UFSM/PróPublicações Internacionais. C.F. Mello, M.A. Rubin and J.F. Oliveira are the recipients of CNPq fellowships (\#476551/2009-9, \#304029/2010-6 and \#303747/20102 , respectively). 


\section{References}

1. Astle S, Thornton S, Slater DM. Identification and localization of prostaglandin E2 receptors in upper and lower segment human myometrium during pregnancy. Mol Hum Reprod 2005; 11: 279-287, doi: 10.1093/molehr/gah158.

2. Gibb W. The role of prostaglandins in human parturition. Ann Med 1998; 30: 235-241, doi: 10.3109/ 07853899809005850.

3. ACOG. ACOG: Practice Bulletin No. 107: Induction of labor. Obstet Gynecol 2009; 114: 386-397.

4. Grignaffini A, Soncini E, Anfuso S, Ronzoni E. [Dinoprostone: slow release vaginal insert (Propess) and intracervical gel (Prepidil) for the induction of labour with unriped cervix]. Minerva Ginecol 2004; 56: 413-418.

5. Snegovskikh V, Park JS, Norwitz ER. Endocrinology of parturition. Endocrinol Metab Clin North Am 2006; 35: 173191, viii, doi: 10.1016/j.ecl.2005.09.012.

6. Pieber D, Allport VC, Hills F, Johnson M, Bennett PR. Interactions between progesterone receptor isoforms in myometrial cells in human labour. Mol Hum Reprod 2001; 7 : 875-879, doi: 10.1093/molehr/7.9.875.

7. Smith R, Mesiano S, McGrath S. Hormone trajectories leading to human birth. Regul Pept 2002; 108: 159-164, doi: 10.1016/S0167-0115(02)00105-2.

8. Vidaeff AC, Ramin SM. Potential biochemical events associated with initiation of labor. Curr Med Chem 2008; 15: 614-619, doi: 10.2174/092986708783769786.

9. Chaim W, Mazor M. The relationship between hormones and human parturition. Arch Gynecol Obstet 1998; 262: 4351, doi: 10.1007/s004040050226.

10. Smith R, Smith JI, Shen X, Engel PJ, Bowman ME, McGrath $S A$, et al. Patterns of plasma corticotropin-releasing hormone, progesterone, estradiol, and estriol change and the onset of human labor. J Clin Endocrinol Metab 2009; 94 : 2066-2074, doi: 10.1210/jc.2008-2257.

11. Lofgren $M$, Backstrom $T$. High progesterone is related to effective human labor. Study of serum progesterone and 5alpha-pregnane-3,20-dione in normal and abnormal deliveries. Acta Obstet Gynecol Scand 1997; 76: 423-430, doi: 10.3109/00016349709047823.

12. Boroditsky RS, Reyes FI, Winter JS, Faiman C. Maternal serum estrogen and progesterone concentrations preceding normal labor. Obstet Gynecol 1978; 51: 686-691.

13. Mathur RS, Landgrebe S, Williamson HO. Progesterone, 17-hydroxyprogesterone, estradiol, and estriol in late pregnancy and labor. Am J Obstet Gynecol 1980; 136: 25-27.

14. Sennstrom MB, Ekman G, Westergren-Thorsson G, Malmstrom A, Bystrom B, Endresen $U$, et al. Human cervical ripening, an inflammatory process mediated by cytokines. Mol Hum Reprod 2000; 6: 375-381, doi: 10.1093/ molehr/6.4.375.

15. Osman I, Young A, Ledingham MA, Thomson AJ, Jordan F, Greer IA, et al. Leukocyte density and pro-inflammatory cytokine expression in human fetal membranes, decidua, cervix and myometrium before and during labour at term. Mol Hum Reprod 2003; 9: 41-45, doi: 10.1093/molehr/ gag001.

16. Robertson SA, Christiaens I, Dorian CL, Zaragoza DB, Care AS, Banks AM, et al. Interleukin-6 is an essential determinant of on-time parturition in the mouse. Endocrinology 2010; 151: 3996-4006, doi: 10.1210/ en.2010-0063.

17. Brown AG, Leite RS, Strauss JF III. Mechanisms underlying "functional" progesterone withdrawal at parturition. Ann N Y Acad Sci 2004; 1034: 36-49, doi: 10.1196/annals.1335.004.

18. Feinshtein V, Ben-Zvi Z, Sheiner E, Amash A, Sheizaf B, Holcberg G. Progesterone levels in cesarean and normal delivered term placentas. Arch Gynecol Obstet 2010; 281: 387-392, doi: 10.1007/s00404-009-1125-x.

19. Zakar T, Hertelendy F. Progesterone withdrawal: key to parturition. Am J Obstet Gynecol 2007; 196: 289-296, doi: 10.1016/j.ajog.2006.09.005.

20. Merlino AA, Welsh TN, Tan H, Yi LJ, Cannon V, Mercer BM, et al. Nuclear progesterone receptors in the human pregnancy myometrium: evidence that parturition involves functional progesterone withdrawal mediated by increased expression of progesterone receptor-A. J Clin Endocrinol Metab 2007; 92: 1927-1933, doi: 10.1210/jc.2007-0077.

21. Bishop $\mathrm{EH}$. Pelvic scoring for elective induction. Obstet Gynecol 1964; 24: 266-268.

22. Tan PC, Daud SA, Omar SZ. Concurrent dinoprostone and oxytocin for labor induction in term premature rupture of membranes: a randomized controlled trial. Obstet Gynecol 2009; 113: 1059-1065.

23. Pevzner L, Powers BL, Rayburn WF, Rumney P, Wing DA. Effects of maternal obesity on duration and outcomes of prostaglandin cervical ripening and labor induction. Obstet Gynecol 2009; 114: 1315-1321, doi: 10.1097/AOG. Ob013e3181bfb39f.

24. Dietz PM, England LJ, Callaghan WM, Pearl M, Wier ML, Kharrazi M. A comparison of LMP-based and ultrasoundbased estimates of gestational age using linked California livebirth and prenatal screening records. Paediatr Perinat Epidemiol 2007; 21 (Suppl 2): 62-71, doi: 10.1111/j.13653016.2007.00862.x.

25. Savitz DA, Terry JW Jr, Dole N, Thorp JM Jr, Siega-Riz AM, Herring $\mathrm{AH}$. Comparison of pregnancy dating by last menstrual period, ultrasound scanning, and their combination. Am J Obstet Gynecol 2002; 187: 1660-1666, doi: 10.1067/mob.2002.127601.

26. Chervenak FA, Skupski DW, Romero R, Myers MK, SmithLevitin M, Rosenwaks $Z$, et al. How accurate is fetal biometry in the assessment of fetal age? Am J Obstet Gynecol 1998; 178: 678-687, doi: 10.1016/S00029378(98)70477-6.

27. Pevzner L, Rayburn WF, Rumney P, Wing DA. Factors predicting successful labor induction with dinoprostone and misoprostol vaginal inserts. Obstet Gynecol 2009; 114: 261267, doi: 10.1097/AOG.0b013e3181ad9377.

28. Renthal NE, Chen CC, Williams KC, Gerard RD, PrangeKiel J, Mendelson CR. miR-200 family and targets, ZEB1 and ZEB2, modulate uterine quiescence and contractility during pregnancy and labor. Proc Natl Acad Sci U S A 2010; 107: 20828-20833, doi: 10.1073/pnas.1008301107.

29. Hardy DB, Janowski BA, Corey DR, Mendelson CR. Progesterone receptor plays a major antiinflammatory role in human myometrial cells by antagonism of nuclear factorkappaB activation of cyclooxygenase 2 expression. $\mathrm{Mol}$ 
Endocrinol 2006; 20: 2724-2733, doi: 10.1210/me.2006-0112.

30. Patel FA, Challis JR. Cortisol/progesterone antagonism in regulation of 15-hydroxysteroid dehydrogenase activity and mRNA levels in human chorion and placental trophoblast cells at term. J Clin Endocrinol Metab 2002; 87: 700-708, doi: 10.1210/jc.87.2.700.

31. Giangrande $\mathrm{PH}, \mathrm{McDonnell} \mathrm{DP}$. The $\mathrm{A}$ and $\mathrm{B}$ isoforms of the human progesterone receptor: two functionally different transcription factors encoded by a single gene. Recent Prog Horm Res 1999; 54: 291-313.

32. Mesiano S, Chan EC, Fitter JT, Kwek K, Yeo G, Smith R. Progesterone withdrawal and estrogen activation in human parturition are coordinated by progesterone receptor $A$ expression in the myometrium. J Clin Endocrinol Metab 2002; 87: 2924-2930, doi: 10.1210/jc.87.6.2924.
33. Mesiano S, Welsh TN. Steroid hormone control of myometrial contractility and parturition. Semin Cell Dev Biol 2007; 18: 321-331, doi: 10.1016/j.semcdb.2007.05.003.

34. Allport VC, Pieber D, Slater DM, Newton R, White JO, Bennett PR. Human labour is associated with nuclear factor-kappaB activity, which mediates cyclo-oxygenase-2 expression and is involved with the 'functional progesterone withdrawal'. Mol Hum Reprod 2001; 7: 581-586, doi: 10.1093/molehr/7.6.581.

35. Madsen G, Zakar T, Ku CY, Sanborn BM, Smith R, Mesiano $S$. Prostaglandins differentially modulate progesterone receptor-A and -B expression in human myometrial cells: evidence for prostaglandin-induced functional progesterone withdrawal. J Clin Endocrinol Metab 2004; 89: 1010-1013, doi: 10.1210/jc.2003-031037. 